Article

\title{
Interpreting Pattern in Plant-Soil Feedback Experiments with Co-occurring Invasive Species: A Graphical Framework and Case Study
}

\author{
Emma Oschrin * $\mathbb{D}$ and Heather L. Reynolds $\mathbb{D}$ \\ Department of Biology, Indiana University, Bloomington, IN 47405, USA; hlreynol@indiana.edu \\ * Correspondence: eoschrin@indiana.edu
}

Received: 1 April 2020; Accepted: 14 May 2020; Published: 16 May 2020

\begin{abstract}
Despite the ubiquity of multiple plant invasions, the underlying mechanisms of invasive-invasive interactions remain relatively unknown. Given the importance of plant-soil feedback (PSF) in contributing to single species invasions, it may be an important factor influencing invasive-invasive species interactions as well. PSF between multiple invaders has rarely been examined, but could inform the nature of invasive-invasive interactions and advance understanding of how multiple invaders impact plant communities. Alternative mechanisms of plant invasions include novel weapons and enemy escape. We develop graphical PSF predictions based on these mechanisms and other possible invasive-invasive dynamics. Comparing these predictions to observed results is a first step in interpreting PSF among co-occurring invasive species. We illustrate this with a case study of net pairwise PSF among three common invaders of tallgrass prairie: Lotus corniculatus (birdsfoot trefoil), Phalaris arundinacea (reed canarygrass), and Cirsium arvense (Canada thistle). We found that feedback among all pairwise combinations of these invasive species was neutral. Neutral feedback can arise from a mutual lack of soil borne pathogens, consistent with the enemy escape hypothesis, although we cannot rule out shared benefit from generalist mutualists. While both facilitative and competitive interactions among these three species have previously been shown, our data suggest that such interactions are unlikely to operate through a legacy effect of PSF. Our results inform follow-up PSF experiments that would help to confirm the existence and nature of PSF interactions among these species.
\end{abstract}

Keywords: co-occurring invasive species; plant-soil feedback; invasive-invasive interactions; enemy escape; invasive feedback; invasive plants; community dynamics

\section{Introduction}

Given the scale and scope of plant invasions [1], ecosystems are commonly co-invaded by multiple exotic species [2]. Despite this ubiquity of co-occurring invasions, the field of invasion biology has been dominated by research and theory on single species invasions, and attention to the mechanisms and impacts of co-occurring invasive species is a critical frontier [2,3]. A diversity of invasive-invasive interactions have been observed, including facilitative [4,5], competitive [6], and neutral [7] interactions, with varying impacts on the native community $[8,9]$. The underlying mechanisms of invasive-invasive interactions are not well understood and an ability to predict when interactions may be facilitative vs. competitive vs. neutral is lacking. Given that plant-soil feedback (PSF) has been implicated as a key driver of single species plant invasions [10-12], it may thus be an important mechanism influencing the nature of invasive-invasive species interactions.

Plant-soil feedback (PSF) occurs when plants change the abiotic and/or biotic conditions of their soil, which in turn affects the success of con- and heterospecific plants $[13,14]$. PSFs have substantial 
implications for community composition and invasion dynamics. Often, native species produce negative PSF, a stabilizing force promoting species' coexistence, which allows for diverse communities to persist over time [14-16]. In contrast, invasive species often benefit from neutral to positive feedback, where neutral feedback can be attributed to pathogen escape (in accordance with the enemy escape hypothesis) and positive feedback can stem from the ability to associate with more generalist beneficial mutualists (enhanced mutualism) $[11,12,15,17]$. If an invasive species exhibits neutral or positive feedback, especially when competing against native plants experiencing negative feedback, it is likely to increase its presence in the community over time, leading to dominance $[12,17,18]$. These outcomes have been demonstrated when conducting PSF studies between multiple native species, or with a native and a single invader [19].

To date, PSF between multiple invaders has rarely been examined, but could shed light on the nature of invasive-invasive interactions. Here, we focus on net pairwise feedback, which examines the growth of two species in their own and in the other's soil and can inform how plants impact each other in communities [14]. For example, positive invasive-invasive net pairwise PSF is a destabilizing force that would predict local competitive exclusion among co-occurring invasive species [14,20]. A few PSF studies have included multiple invasive species, finding varying degrees of evidence for positive invasive-invasive feedback. In a deciduous forest system, there was clear evidence of positive PSFs between three co-occurring invasive shrubs [21]. When comparing PSFs in rare versus invasive plants of Canadian old-fields, invasive species were found to experience positive feedback in self-conditioned soil relative to other-conditioned soil, although the 'other' soil treatment was a combination of both native- and invasive-trained soils [11]. In a xeric shrubland in Brazil, arbuscular mycorrhizal fungi isolated from the roots of four invasive plant species (and then pooled) significantly promoted all of the invasive species to varying degrees [22]. While these studies begin to address PSFs among invasive species, only Kuebbing et al. considered net pairwise feedback between invaders [21].

We can theorize about the possible outcomes of a net pairwise feedback study among invasive species. If each species grows best in conspecific soil (positive PSF dynamics), possible explanations for this pattern could be that each species possesses novel weapons that negatively impact heterospecifics disproportionately and/or competition for limiting soil resource(s) (Figure 1a). Alternatively, if each species grows better in soil trained by heterospecifics (negative PSF dynamics), this could indicate that the species are niche-partitioned, or possibly that there is some mechanism of joint facilitation, such as reciprocal promotion of host-specific soil mutualisms (Figure 1b). If both species respond similarly to con- and heterospecific soil types—indicative of neutral PSF dynamics-this could be due to both invasives having escaped soil-borne pathogens (mutual enemy escape), to generalist soil mutualists (mutual enhanced mutualism) or possibly to a nitrogen fixer facilitating both species equally (Figure 1c). Explicit tests of net pairwise PSF among co-occurring invasive species are needed in order to explore the possible range of PSF dynamics, search for patterns, and build the capacity to predict the outcomes of co-occurring invasions.

The aim of this study was to contribute to understanding the role of PSFs in co-occurring invasive species dynamics. We conducted a net pairwise PSF study of three perennial plant species that commonly invade grasslands, including tallgrass prairie restorations. Prior work with these three species has demonstrated that the nitrogen fixer, Lotus corniculatus, has a facilitative effect on both of the other invaders, Phalaris arundinacea and Cirsium arvense [8]. Conversely, P. arundinacea and C. arvense compete with each other and have a negative impact on L. corniculatus when co-occurring [8]. This study sought to investigate whether these invasive-invasive interactions were mediated by plant-soil interactions, either microbial or abiotic. 

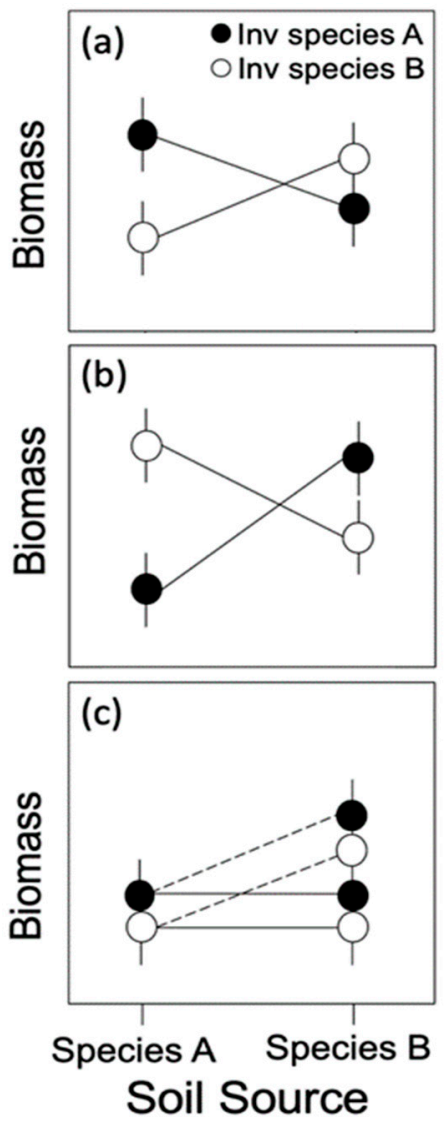

Figure 1. Theoretical outcomes of invasive-invasive net pairwise plant-soil feedback could potentially include (a) positive feedback due to novel weapons and/or competition for limiting soil resource(s), (b) negative feedback indicative of niche partitioning or joint facilitation, or (c) neutral feedback due to mutual enemy escape and/or generalist soil mutualists (solid horizontal lines) or facilitation by a nitrogen fixer (dashed lines).

\section{Materials and Methods}

\subsection{Overview}

A two-phase pairwise plant-soil feedback experiment [14] was conducted. In Phase I, live prairie soil was trained by monocultures of invasive species for 20 weeks. In Phase II, seedlings of each invasive species were individually grown in soil that had been trained by con- and heterospecific plants.

\subsection{Phase I: Soil Conditioning}

To expose plants to a representative soil microbial community, live prairie topsoil was mixed in a 1:2 ratio with sterile background soil. Live prairie soil was collected from multiple restored mesic prairie sites at Kankakee Sands, a Nature Conservancy site in Northern Indiana $\left(41.0472^{\circ} \mathrm{N}\right.$, $87.4511^{\circ} \mathrm{W}$ ) in May 2016. Using a clean spade-tipped shovel, soil was collected to a depth of $23 \mathrm{~cm}$ at several haphazardly selected locations within each of five restored sites, to yield $\sim 38 \mathrm{~L}$ of pooled live soil. Soil was sieved through a 6-mm mesh size, mixed to ensure homogeneity, and stored in clean, covered plastic tubs at $4{ }^{\circ} \mathrm{C}$ for three days. Background soil consisted of a 1:1 ratio of washed river sand and Indiana topsoil which had been autoclaved at $80^{\circ} \mathrm{C}$ in a steamer cart (Hummert International, Earth City, MO, USA) for two 2-h periods with a 24-h resting period in between. River sand was provided by Young Trucking, Inc. in Martinsville, IN and the topsoil was obtained from development sites in the Bloomington, IN area. Pots were filled with a bottom layer of $635 \mathrm{~mL}$ of sterile background 
soil followed by an equal amount of live soil, and capped with a 3-cm layer of additional sterile background soil to inhibit weeds and cross-contamination from splash during watering.

The soil was then conditioned by three invasive species, each in monoculture. The invasive species are all common invaders of Midwest prairie habitat and known to co-occur at Kankakee Sands. The invasive species included the forb, Cirsium arvense (Canada thistle), the nitrogen-fixing legume, Lotus corniculatus (birdsfoot trefoil), and the grass, Phalaris arundinacea (reed canarygrass). Cirsium arvense was likely accidentally introduced to North America in the 1600 s as a contaminant in crop seed [23]. Lotus corniculatus is thought to have been intentionally introduced for use as a forage crop over a hundred years ago [24]. Phalaris arundinacea was introduced to the United States in the mid-1800s [25]. Cirsium arvense seeds were purchased from Herbiseed (Twyford, England), L. corniculatus seeds were purchased from Byron Seeds (Rockville, IN, USA) and P. arundinacea seeds were purchased from Deer Creek Seed (Windsor, WI, USA). The invasive species were initially grown in 27.79-cm by 54.46-cm germination flats (T.O. Plastics, Clearwater, MN, USA) in a sterile growing medium (Metro-Mix 360, Sun Gro Horticulture, Vancouver, CA, USA) for approximately three weeks. Three seedlings were then transplanted directly into 2.8-L pots (Dillen Products Inc., Middlefield, $\mathrm{OH}, \mathrm{USA}$ ) which had been surface-sterilized in $0.52 \%$ Physan 20 and filled with the above-mentioned soil mixture.

Each of the three invasive monocultures was replicated eight times and arranged in a randomized block design (each block contained one replicate of each invasive species) in a temperature-controlled greenhouse at Indiana University. Supplemental lighting was provided with 1000-watt, high-pressure sodium lights to achieve a 15-h, 9-h light-dark cycle characteristic of a summer photoperiod. Phase I soil was conditioned for 20 weeks (June-October).

\subsection{Phase II: Species Response}

Surface-sterilized deepots (25-cm deep, 6.4-cm wide) were bottom-lined with clean paper towels and filled with $250 \mathrm{~mL}$ of the same sterile background soil as described for Phase I above. Live-conditioned soil from each Phase I mesocosm was sieved through a 4-mm sieve onto sterile wax paper and divided into four $150-\mathrm{mL}$ aliquots. One aliquot was added to each of four deepots $(33.3 \%$ of pot volume) and capped with $50 \mathrm{~mL}$ of sterile soil. Deepot quads were then planted with a six-week old seedling plug from each of the three invasive species. This approach resulted in a full-factorial design, with independent replicates of each invasive species grown in conspecific soil as well as in soil conditioned by each of the other two invasive species. To prevent cross contamination amongst treatments and replicates, all materials that came into contact with soil were either surface-sterilized or disposed of between the harvest of conditioned soil from each Phase I pot and between the plantings of seedlings into each Phase II pot.

Deepots were arranged in a randomized block design on benches surface-sterilized with $0.52 \%$ Physan 20; given the full-factorial design, there were also eight blocks for Phase II pots. Plants were allowed to grow for three months (October-January) in the same temperature-controlled greenhouse as Phase I microcosms. The supplemental lighting regime was also consistent with Phase I conditions.

\subsection{Data Collection}

During Phase II set up, extra soil from the Phase I pots was stored in sterile plastic bags at $4{ }^{\circ} \mathrm{C}$ for 3-5 days (depending on block) prior to analysis for available ammonium and nitrate. A single 5-g sample of the soil from each Phase I pot was extracted in $10 \mathrm{~mL} 2 \mathrm{M} \mathrm{KCl}$ solution. These samples were placed on an orbital shaker for $1 \mathrm{~h}$ prior to being centrifuged at 2400 Revolutions per Minute for $10 \mathrm{~min}$. After the supernatant was separated from the soil, the supernatant was filtered using Whatman filter paper No. 1001-110 (GE Healthcare Life Sciences, Buckinghamshire, UK) and frozen until analyses could be conducted. A QuikChem 8500 Series 2 Autoanalyzer (Lachat Instruments, Hach Company, Loveland, CO, USA) was used to analyze samples for ammonium and nitrate. At the end of Phase II, 
aboveground biomass from each deepot was clipped at the soil surface, dried in a $60{ }^{\circ} \mathrm{C}$ drying oven to a constant weight, and weighed.

\subsection{Statistical Analysis}

To test for PSF, we used a linear mixed model (Type II ANOVA) with Phase II aboveground biomass as the response variable, and Phase I soil source and Phase II response plant identity as factors with all possible interactions. Soil source and response plant identity were fixed effects and block was a random effect. Plan-soil feedback is indicated by the interaction between Phase I soil source and Phase II response plant identity, with non-neutral PSF indicated when the interaction is significant.

In addition to the linear mixed model, we calculated interaction coefficients $\left(I_{S}\right)$ for each pair of species. Interaction coefficients determine the sign and magnitude of pair-wise feedback and were calculated using the following equation [14]

$$
I_{s}=A_{a}-B_{a}-A_{b}+B_{b}
$$

where A and B represent the Phase II response plants and the subscripts a and $\mathrm{b}$ represent the Phase I soil source. As such, $A_{a}$ represents the growth of species $A$ in soil conditioned by species $A$ and $A_{b}$ represents the growth of species $A$ in soil conditioned by species $B$. Conversely, $B_{b}$ represents the growth of species $B$ in soil conditioned by conspecifics and $B_{a}$ represents the growth of species $B$ in soil conditioned by heterospecifics. Single-sample, two-sided $t$-tests were used to assess whether the pairwise feedback differed from zero, which is also indicative of non-neutral PSF.

Ammonia and nitrate data were analyzed using linear mixed models (Type II ANOVA) with treatment as a fixed effect, block as a random effect, and ammonia and nitrate as the dependent variable, respectively.

Visual diagnostics and the Shapiro-Wilk test were performed on the residuals of the various models to test for normality. No transformations of the response plant biomass data or nitrate data were necessary; ammonia data were square root transformed to meet model assumptions. All models were built using the "lme4" package [26] in the statistical programs R version 3.6.1 and RStudio version 1.1.442 [27].

\section{Results}

Phase I soil source was a weakly significant factor $(d f=2, p=0.06$, Table 1$)$ and Phase II response plant identity was a significant factor $\left(d f=2, p=1.92 \times 10^{-8}\right.$, Table 1$)$ in the linear mixed effects model for Phase II aboveground biomass. However, there was no significant two-way interaction between Phase I soil source and Phase II response plant identity for this model $(d f=4, p=0.87$, Table 1$)$, indicating neutral PSF. The model yielded a marginal $\mathrm{R}^{2}$ value (associated with fixed effects) of 0.356 and a conditional $\mathrm{R}^{2}$ value (associated with both fixed and random effects) of 0.402 .

Table 1. Results of linear mixed model examining Phase I soil source, Phase II response plant identity, and the interaction between these two factors.

\begin{tabular}{ccc}
\hline Factor & d.f. & $p$-Value \\
\hline Response plant identity & 2 & $1.922 \times 10^{-8}$ \\
Soil source & 2 & 0.065 \\
Response plant identity $\times$ Soil source & 4 & 0.873 \\
\hline
\end{tabular}

Consistent with the non-significant PSF interaction, the interaction coefficient for each pair of invasive species did not differ significantly from zero, also indicating neutral net pairwise feedback. Mean interaction coefficients were -0.33 for $L$. corniculatus and C. arvense $(d f=7, p=0.53$; Figure 2), -0.21 for L. corniculatus and P. arundinacea ( $d f=7, p=0.69$; Figure 3$)$, and 0.076 for P. arundinacea and 
C. arvense $(\mathrm{df}=7, p=0.76$, Figure 4$)$. Neither ammonia $(d f=2, p=0.15)$ nor nitrate $(d f=2, p=0.23)$ levels differed significantly in the Phase I pots at the end of the 20-week training period.

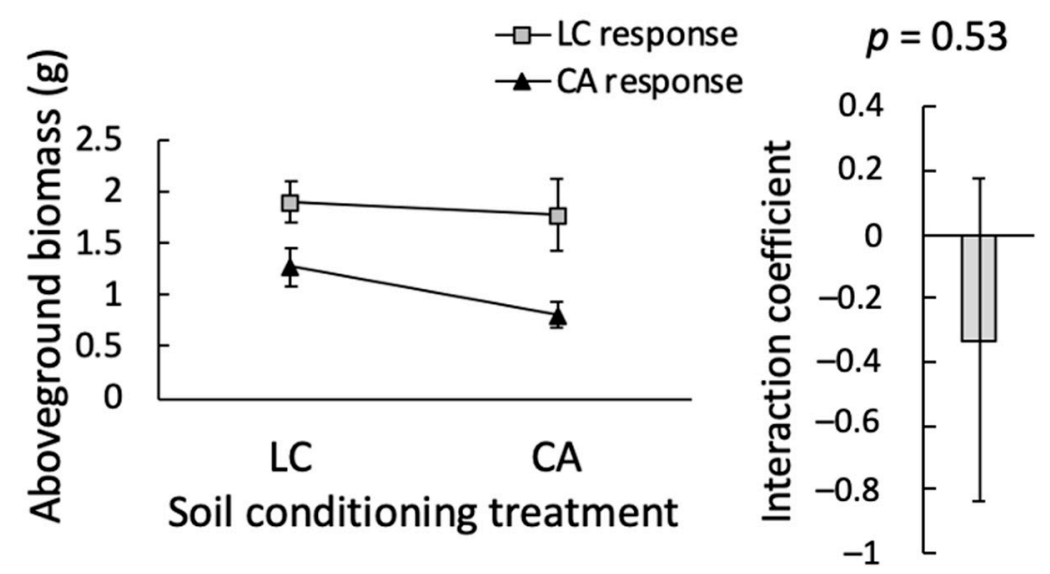

Figure 2. Feedback between Lotus corniculatus (LC) and Cirsium arvense (CA). These species experience neutral feedback. Neither species is significantly affected by soil conditioning treatment, although C. arvense does grow slightly better in soil conditioned by L. corniculatus. The inset shows the interaction coefficient between these species, which does not differ significantly from zero $(p=0.53)$, also indicative of neutral feedback. Bars indicate \pm SE.

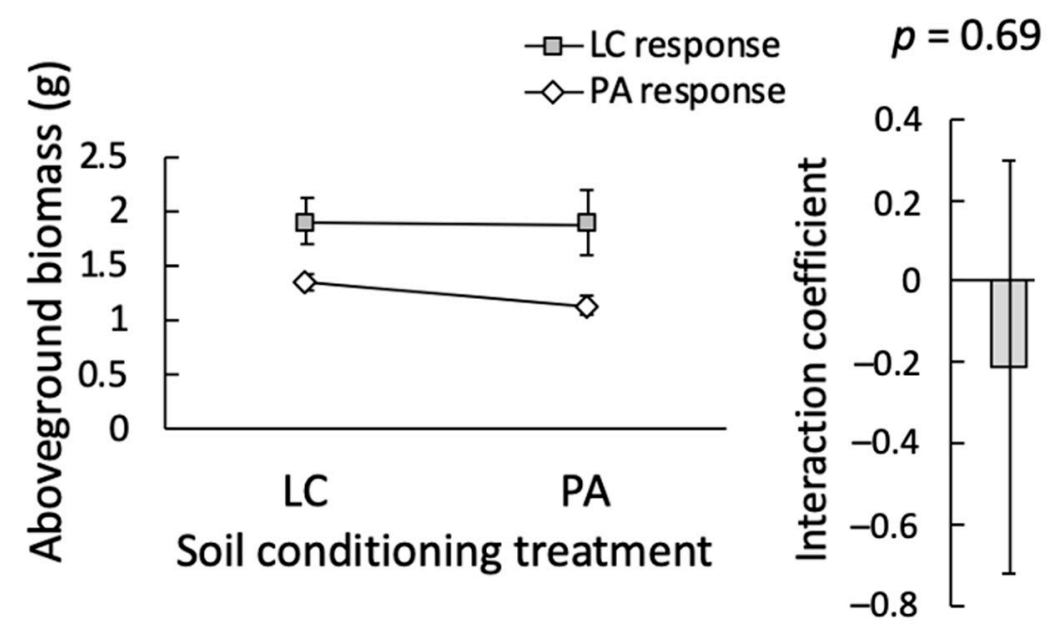

Figure 3. Feedback between Lotus corniculatus (LC) and Phalaris arundinacea (PA). These species experience neutral feedback. Neither species is significantly affected by soil conditioning treatment although P. arundinacea does grow slightly better in soil conditioned by L. corniculatus. The inset shows the interaction coefficient between these species, which does not differ significantly from zero $(p=0.69)$, also indicative of neutral feedback. Bars indicate \pm SE. 


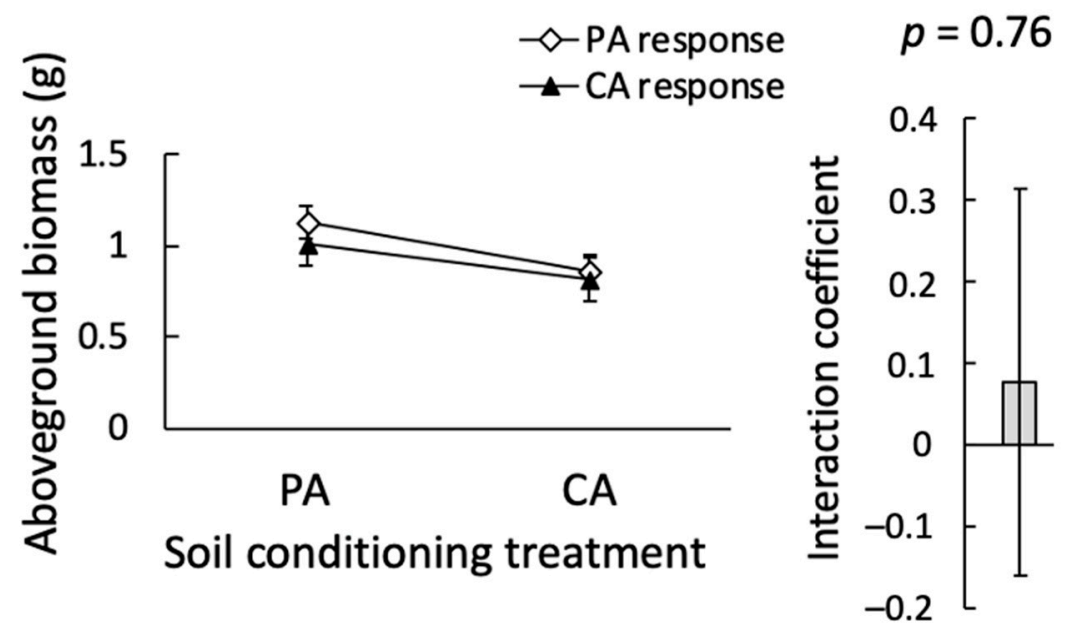

Figure 4. Feedback between Phalaris arundinacea (PA) and Cirsium arvense (CA). These species experience neutral feedback. Neither species is significantly affected by soil conditioning treatment although both P. arundinacea and C. arvense grow slightly better in soil conditioned by P. arundinacea. The inset shows the interaction coefficient between these species, which does not differ significantly from zero $(p=0.76)$, also indicative of neutral feedback. Bars indicate \pm SE.

\section{Discussion}

Our results suggest that three co-occurring common prairie invaders exhibit neutral, rather than positive or negative, net pairwise feedback dynamics. Neutral feedback among invasive species could indicate that both species have escaped species-specific, soil-borne pathogens, consistent with the enemy escape hypothesis [28]. Alternatively, it could be indicative of shared soil mutualists, consistent with the enhanced mutualisms hypothesis [10], or of both species benefiting from added nitrogen when nitrogen-fixers are present. Based on the results from our experiment, the lack of either positive or negative pairwise feedback among these three invasives also suggests that, when they co-occur, they will not significantly promote or hinder each other via novel weapons, niche partitioning or some mechanism of reciprocal facilitation.

If both species have escaped soil-borne pathogens, we would not expect them to accumulate species specific pathogens that are known to contribute to negative plant-soil feedback [11]. While negative feedback has mostly been linked to species-specific pathogens, soil mutualists also have the potential to generate this type of feedback [29]. For example, if a species of plant promotes a species of fungus that benefits another plant species more than its original host (and the reciprocal, or a neutral effect, is true for a second species of plant and fungus), this will lead to negative net pairwise feedback. In addition to escaping pathogens from their native range, invasives may also be able to take advantage of generalist mutualists in the soil $[10,30]$. Consequently, if neither species accumulates soil-borne pathogens and/or both species benefit from shared mutualists, soil trained by a con- versus a heterospecific plant would not be expected to have a noticeable difference in plant growth.

We might also see neutral pairwise feedback among invasives if both species are similarly positively impacted when grown in soil trained by a nitrogen-fixing species. If both species benefit from added nitrogen in nitrogen-fixer-trained soil, there would not be a pattern of an interaction, but simply a main effect of soil source. We observed little evidence for this mechanism of neutral feedback in our study. The main effect of soil source was only marginally significant, reflecting that while both non-nitrogen-fixing species tended to have slightly higher biomass when grown in soil trained by the nitrogen-fixer, L. corniculatus did not clearly benefit from growing in self-trained versus non-nitrogen-fixer trained soil. Furthermore, there were no statistically significant differences in ammonium or nitrate levels in Phase-I-trained soil. Lotus corniculatus was observed to reach a higher biomass than either of the other two, non-nitrogen fixing species. This boost in biomass may have been due to L. corniculatus' nitrogen-fixing activity, but if so, there was not a significant legacy effect of 
this activity on Phase II soil. This result contrasts with evidence from a prior study of facilitation of C. arvense and P. arundinacea via nitrogen inputs by L. corniculatus [8]. In the prior study, facilitation was observed when L. corniculatus was grown with each of the other species. Thus, continuous nitrogen enrichment by the presence of a living nitrogen-fixer may be necessary for a substantial facilitative effect to occur, especially if fixed ammonium is converted to nitrate, which readily leaches from the soil, thus minimizing the carry-over effects of Phase I fixed nitrogen to Phase II plants.

Invasive species may be able to outcompete natives in part due to novel weapons, allelopathic chemicals that are exuded from the roots [31]. In the invasive species' native range, neighboring plants that had evolved together would be adapted to the allelochemicals. In the invaded range, natives that had not co-evolved with the chemicals would be negatively impacted. Invasive species with novel weapons have the potential to harm other invaders as well as native species. If we had observed invasive species with novel weapons, we would expect invaders to reach a higher aboveground biomass in self-conditioned soil as opposed to other-conditioned soil. If both invaders possessed novel weapons, this would manifest as an interaction between these species. However, we did not find the expected positive PSF signal of this pattern, suggesting that the invaders in this study do not negatively impact each other via novel weapons. Similarly, the absence of positive PSF suggests that our invasive species may not engage in competition for limiting soil resources, at least under the conditions of our experiment.

We also did not see evidence of soil resource niche partitioning or reciprocal promotion of host-specific soil mutualists among the three invasives in our study. Soil resource niche partitioning is a mechanism of abiotic PSF [32]. If the invasive species were partitioned in soil resource niche space, they would each be utilizing soil resources in a species-specific way [33]. As such, when an individual was grown in other-trained soil, it would have access to more of the specific resources it needs than when grown in self-trained soil. As a result of this species-specific resource use, each species would reach a higher aboveground biomass in other-trained soil and we would see evidence of an interaction. Since we do not have evidence of an interaction, we can assert that the invasive species used in this study are not noticeably niche partitioned, at least under the conditions of our experiment. This interpretation is consistent with earlier work finding that these species significantly impact each other when grown in competition [8].

\section{Conclusions}

From our measures of aboveground biomass, it appears that all invaders grow similarly in selfand other-trained soils. Considering the totality of our data, we conclude that this result of neutral PSF among three invasive species is most consistent with a lack of species-specific pathogens and/or the presence of shared mutualists rather than facilitative effects from nitrogen-fixing invasive species.

In order to conclusively determine if mutual enemy escape, generalist mutualists, or nitrogen enrichment (in situations where a nitrogen-fixing invasive species is present) is contributing to the neutral feedback found here, plant-soil feedback experiments comparing whole-soil and inoculum would be informative. Inoculum at low volumes $(<5 \%)$ enables the isolation of the effects of soil biota such as beneficial microbes and pathogens, while use of a higher volume of inoculum (at least 30\%) yields a whole-soil PSF experiment that also allows for the detection of abiotic factors such as nutrients and allelochemicals [32]. If enemy escape from host-specific pathogens and/or benefits of generalist mutualists was occurring, Phase II plants exposed to low-volume inoculum would be expected to perform equally well regardless of whether inoculum was sourced from con- versus heterospecific Phase I soil. If facilitation via nitrogen enrichment from nitrogen-fixing species was occurring, Phase II plants exposed to low-volume inoculum would not be expected to perform as well as plant exposed to a higher volume of inoculum. To distinguish between mutual enemy escape versus generalist mutualists, controls with sterilized inoculum could be included, followed by microscopic and/or molecular analyses and treatments with isolated soil pathogens or mutualists as relevant. 
Author Contributions: Conceptualization, E.O. and H.L.R.; methodology, E.O. and H.L.R.; software, E.O.; validation, E.O. and H.L.R.; formal analysis, E.O.; investigation, E.O.; resources, H.L.R.; data curation, E.O.; writing-original draft preparation, E.O.; writing—review and editing, E.O. and H.L.R.; visualization, E.O.; supervision, E.O. and H.L.R.; project administration, E.O.; funding acquisition, H.L.R.. All authors have read and agreed to the published version of the manuscript.

Funding: This research was supported by Indiana University Department of Biology funds awarded to H.L.R. and E.O. This research received no external funding.

Acknowledgments: Thanks to Lilian Golzarri Arroyo of the Indiana University Biostatistics Consulting Center for assisting with data analysis. Thanks to Ted Anchor and Stuart Orr at the Kankakee Sands Nature Conservancy Site, in particular, for their guidance in regard to target species and soil collection.

Conflicts of Interest: The authors declare no conflict of interest.

\section{References}

1. Mack, R.N.; Simberloff, D.; Lonsdale, W.M.; Evans, H.; Clout, M.; Bazzaz, F.A. Biotic Invasions: Causes, Epidemiology, Global Consequences, and Control. Ecol. Appl. 2000, 10, 689-710. [CrossRef]

2. Kuebbing, S.E.; Nunez, M.A.; Simberloff, D. Current Mismatch between Research and Conservation Efforts: The Need to Study Co-Occurring Invasive Plant Species. Biol. Conserv. 2013, 160, 121-129. [CrossRef]

3. Simberloff, D.; Von Holle, B. Positive Interactions of Nonindigenous Species: Invasional Meltdown? Biol. Invasions 1999, 1, 21-32. [CrossRef]

4. Vitousek, P.M.; Walker, L.R. Biological Invasion by Myrica Faya in Hawai'i: Plant Demography, Nitrogen Fixation, Ecosystem Effects. Ecol. Monogr. 1989, 59, 247-265. [CrossRef]

5. Wang, C.; Wei, M.; Wang, S.; Wu, B.; Cheng, H. Science of the Total Environment Erigeron annuus (L.) Pers. and Solidago canadensis L. Antagonistically Affect Community Stability and Community Invasibility under the Co- Invasion Condition. Sci. Total Environ. 2020, 716, 137128. [CrossRef]

6. Pfeifer-Meister, L.; Cole, E.M.; Roy, B.A.; Bridgham, S.D. Abiotic Constraints on the Competitive Ability of Exotic and Native Grasses in a Pacific Northwest Prairie. Oecologia 2008, 155, 357-366. [CrossRef]

7. Cushman, J.H.; Gaffney, K.A. Community-Level Consequences of Invasion: Impacts of Exotic Clonal Plants on Riparian Vegetation. Biol. Invasions 2010, 12, 2765-2776. [CrossRef]

8. Oschrin, E.; Reynolds, H.L. Co-Occurring Invasive Plant Interactions Do Not Predict the Impacts of Invasion in Experimental Tallgrass Prairie Communities. Biol. Invasions 2019, 21, 2417-2430. [CrossRef]

9. Zenni, R.D.; da Cunha, W.L.; Musso, C.; de Souza, J.V.; Nardoto, G.B.; Miranda, H.S. Synergistic Impacts of Co-Occurring Invasive Grasses Cause Persistent Effects in the Soil-Plant System after Selective Removal. Funct. Ecol. 2020, 34, 1102-1112. [CrossRef]

10. Richardson, D.M.; Allsopp, N.; D’Antonio, C.M.; Milton, S.J.; Rejmánek, M. Plant Invasions-the Role of Mutualisms. Biol. Rev. 2000, 75, 65-93. [CrossRef]

11. Klironomos, J.N. Feedback with Soil Biota Contributes to Plant Rarity and Invasiveness in Communities. Nature 2002, 417, 67-70. [CrossRef] [PubMed]

12. Callaway, R.M.; Thelen, G.C.; Rodriguez, A.; Holben, W.E. Soil Biota and Exotic Plant Invasion. Nature 2004, 427, 731-733. [CrossRef] [PubMed]

13. Bever, J.D. Feedback between Plants and Their Soil Communities in an Old Field Community. Ecology 1994, 75, 1965-1977. [CrossRef]

14. Bever, J.D.; Westover, K.M.; Antonovics, J. Incorporating the Soil Community into Plant Population Dynamics: The Utility of the Feedback Approach. J. Ecol. 1997, 85, 561-573. [CrossRef]

15. Kulmatiski, A.; Beard, K.H.; Stevens, J.R.; Cobbold, S.M. Plant-Soil Feedbacks: A Meta-Analytical Review. Ecol. Lett. 2008, 11, 980-992. [CrossRef] [PubMed]

16. Bauer, J.T.; Mack, K.M.L.; Bever, J.D. Plant-Soil Feedbacks as Drivers of Succession: Evidence Form Remnant and Restored Tallgrass Prairies. Ecosphere 2015, 6. [CrossRef]

17. Smith, L.M.; Reynolds, H.L. Euonymus Fortunei Dominance over Native Species May Be Facilitated by Plant-Soil Feedback. Plant Ecol. 2015, 216, 1401-1406. [CrossRef]

18. van der Putten, W.H.; Bardgett, R.D.; Bever, J.D.; Bezemer, T.M.; Casper, B.B.; Fukami, T.; Kardol, P.; Klironomos, J.N.; Kulmatiski, A.; Schweitzer, J.A.; et al. Plant-Soil Feedbacks: The Past, the Present and Future Challenges. J. Ecol. 2013, 101, 265-276. [CrossRef] 
19. Ba, L.; Facelli, E.; Facelli, J.M. Plant-Mycorrhizal Fungi Feedbacks: Potential Accomplices of Avena Barbata's High Invasiveness. Plant Ecol. 2018, 219, 1045-1052. [CrossRef]

20. Molofsky, J.; Bever, J.D. A Novel Theory to Explain Species Diversity in Landscapes: Positive Frequency Dependence and Habitat Suitability. Proc. Biol. Sci. 2002, 269, 2389-2393. [CrossRef]

21. Kuebbing, S.E.; Classen, A.T.; Call, J.J.; Henning, J.A.; Simberloff, D. Plant-Soil Interactions Promote Co-Occurrence of Three Nonnative Woody Shrubs. Ecology 2015, 96, 2289-2299. [CrossRef] [PubMed]

22. de Souza, T.A.F.; de Andrade, L.A.; Freitas, H.; da Silva Sandim, A. Biological Invasion Influences the Outcome of Plant-Soil Feedback in the Invasive Plant Species from the Brazilian Semi-Arid. Microb. Ecol. 2018, 76, 102-112. [CrossRef] [PubMed]

23. Morishita, D.W. Canada Thistle. In Biology and Management of Noxious Rangeland Weeds; Sheley, R.L., Petroff, J.K., Eds.; Oregon State University Press: Corvallis, OR, USA, 1999; pp. 162-174.

24. Mimura, M.; Ono, K.; Goka, K.; Hara, T. Standing Variation Boosted by Multiple Sources of Introduction Contributes to the Success of the Introduced Species, Lotus Corniculatus. Biol. Invasions 2013, 15, 2743-2754. [CrossRef]

25. Lavergne, S.; Molofsky, J. Reed Canary Grass (Phalaris Arundinacea) as a Biological Model in the Study of Plant Invasions. CRC Crit. Rev. Plant Sci. 2004, 23, 415-429. [CrossRef]

26. Bates, D.; Maechler, M.; Bolker, B.; Walker, S. Fitting Linear Mixed-Effects Models Using Lme4. J. Stat. Softw. 2015, 67, 1-48. [CrossRef]

27. Team, R.C. R: A Language and Environment for Statistical Computing; R Foundation for Statistical Computing: Vienna, Austria, 2019.

28. Keane, R.M.; Crawley, M.J. Exotic Plant Invasions and the Enemy Release Hypothesis. Trends Ecol. Evol. 2002, 17, 164-170. [CrossRef]

29. Bever, J.D. Negative Feedback within a Mutualism: Host-Specific Growth of Mycorrhizal Fungi Reduces Plant Benefit. Proc. Biol. Sci. 2002, 269, 2595-2601. [CrossRef] [PubMed]

30. Mitchell, C.E.; Agrawal, A.A.; Bever, J.D.; Gilbert, G.S.; Hufbauer, R.A.; Klironomos, J.N.; Maron, J.L.; Morris, W.F.; Parker, I.M.; Power, A.G.; et al. Biotic Interactions and Plant Invasions. Ecol. Lett. 2006, 9, 726-740. [CrossRef]

31. Callaway, R.M.; Ridenour, W.M. Novel Weapons: Invasive Success and the Evolution of Increased Competitive Ability. Front. Ecol. Environ. 2004, 2, 436-443. [CrossRef]

32. Smith-Ramesh, L.M.; Reynolds, H.L. The next Frontier of Plant-Soil Feedback Research: Unraveling Context Dependence across Biotic and Abiotic Gradients. J. Veg. Sci. 2017, 28, 484-494. [CrossRef]

33. Chase, J.M.; Leibold, M.A. Ecological Niches: Linking Classical and Contemporary Approaches; The University of Chicago Press: Chicago, IL, USA; London, UK, 2003. 